\title{
USIA PUBERTAS DAN MENARCHE TERHADAP TINGGI BADAN MAHASISWA KEBIDANAN
}

\author{
The Age of Puberty and Menarche toward Body Height \\ of Midwifery Students
}

\author{
Rossy Handayani ${ }^{1}$, Irwanto ${ }^{2}$, Dwi Purwanti ${ }^{3}$, Widati Fatmaningrum ${ }^{4}$ \\ ${ }^{1}$ Program Studi Pendidikan Bidan Fakultas Kedokteran Universitas Airlangga Surabaya \\ ${ }^{2}$ Departemen Ilmu Kesehatan Anak Fakultas Kedokteran Universitas Airlangga \\ ${ }^{3}$ Jurusan Kebidanan Poltekkes Kemenkes Surabaya \\ ${ }^{4}$ Departeman Ilmu Kesehatan Masyarakat-Kedokteran Pencegahan Universitas Airlangga \\ (rossy.handayani.16@gmail.com)
}

\begin{abstract}
ABSTRAK
Data Riskesdas tahun 2013 menunjukkan adanya peningkatan prevalensi pendek (stunting) pada remaja usia 16-18 tahun. Pertumbuhan tinggi badan akan mengalami kenaikan kecepatan pertumbuhan pada saat pubertas dan berakhir saat terjadinya menarche. Penelitian ini bertujuan mengetahui hubungan antara usia pubertas dan usia menarche dengan tinggi badan mahasiswa bidan Universitas Airlangga. Jenis penelitian yang digunakan adalah observasional analitik dengan rancangan cross sectional study. Subjek penelitian ini adalah seluruh mahasiswa S1 Pendidikan Bidan Universitas Airlangga yang berusia kurang dari atau sama dengan 20 tahun. Penelitian ini menggunakan total sampling dan uji statistik Mann Whitney. Hasil penelitian diperoleh 102 mahasiswa dengan rata-rata usia 18,8 tahun ( $\mathrm{SD} \pm 0,64)$, tidak ada perbedaan bermakna usia pubertas $(\mathrm{p}=0,643)$ dan usia menarche $(\mathrm{p}=0,198)$ dengan tinggi badan. Kesimpulan penelitian tidak ada hubungan antara usia pubertas dan usia menarche dengan tinggi badan mahasiswa bidan Universitas Airlangga.
\end{abstract}

Kata kunci : Tinggi badan, pubertas, menarche

\begin{abstract}
Riskesdas'data 2013 shows that stunting prevalence in 16-18 years old teenagers in Indonesia is creasing. The height velocity of body height will be increase on puberty and decline to stop at menarche. This study aimed to determinan the association of the age of puberty and menarche and body height of midwifery students Airlangga University. This study's type is an observational cross sectional study. The subjek is the all of the midwifery students Airlangga University that aged less than or equal to 20 years. This study used total sampling and data analysis with Mann Whitney test. The research result was 102 students with an average age of 18.8 years (SD \pm $0,64)$, no significant differences of the onset of puberty $(p=0,643)$ and menarche $(p=0,198)$ and the boody height. Conclution, there are no association between the age of puberty and menarche and body height of midwifery students Airlangga University.
\end{abstract}

Keywords : Body height, puberty, menarche 


\section{PENDAHULUAN}

Prevalensi pendek (stunting) remaja Indonesia berada pada angka cukup tinggi. Data Riset Kesehatan Dasar (Riskesdas) tahun 2013 menunjukkan terdapat peningkatan prevalensi pendek (stunting) pada remaja usia 16-18 tahun dari tahun 2010 , yaitu sebesar $31,2 \%$ menjadi $31,4 \%$. World Health Organization (WHO) tahun 2010 menyebutkan bahwa prevalensi pendek sebesar 30-39\% termasuk dalam kategori masalah kesehatan yang dianggap berat. ${ }^{1}$

Tinggi badan merupakan indikator untuk mengetahui gangguan pertumbuhan fisik yang telah lewat (stunting). Tinggi badan juga salah satu prediktor kualitas sumber daya manusia. Tinggi badan yang pendek menunjukkan bahwa kualitas sumber daya manusia dalam keadaan buruk dan selanjutnya akan menurunkan kemampuan produktivitas bangsa di masa depan. ${ }^{2}$ Pertumbuhan tinggi badan dipengaruhi oleh potensi biologik yang dimiliki, sedangkan tingkat ketercapaian potensi biologik merupakan hasil dari interaksi antara faktor genetik yang merupakan modal dasar dalam mencapai hasil akhir pertumbuhan, dan faktor lingkungan biofisiko psikososial yang merupakan penentu tercapai atau tidaknya potensi bawaan. ${ }^{3}$

Kenaikan tinggi badan bersifat fluktuatif, yaitu pertambahan tinggi badan saat bayi berlangsung cepat, kemudian melambat dan pesat kembali pada masa remaja. Pencapaian tinggi badan akhir dewasa dipengaruhi oleh kecepatan pertumbuhan saat remaja. ${ }^{3}$ Kecepatan pertumbuhan tinggi badan (height velocity) akan mengalami percepatan (pacu tumbuh/height spurt) selama masa pubertas dan berlangsung sekitar dua tahun, akan mencapai puncak kecepatan tinggi badan (Peak Height Velocity/PHV), kemudian sekitar tiga tahun akan mengalami penurunan dan akan terus tumbuh hingga epifise menutup dan pertumbuhan tinggi terhenti. ${ }^{4}$

Kecepatan pertumbuhan dapat diperkirakan secara tidak langsung melalui ketercapaian stadium Tingkat Kematangan Seksual (TKS). Pada anak perempuan, penilaian TKS berdasarkan pertumbuhan rambut pubis dan payudara. Pertumbuhan payudara stadium 2 (breast bud) merupakan tanda awal dari pubertas pada anak pemempuan. Dua tahun setelah awitan pubertas, akan terjadi menstruasi yang pertama (menarche) sebagai tahap akhir masa pubertas. Saat menstruasi terjadi secara periodik, pertumbuhan fisik pada perempuan mulai berakhir dan tinggi badan tidak akan bertambah banyak lagi. ${ }^{5}$ Penelitian ini bertujuan mengetahui hubungan usia pubertas dan usia menarche dengan tinggi badan pada mahasiswa bidan Universitas Airlangga.

\section{BAHAN DAN METODE}

Jenis penelitian yang digunakan adalah observasional analitik dengan metode potong lintang. Penelitian dilaksanakan di Program Studi S1 Pendidikan Bidan Universitas Airlangga pada bulan Maret-April 2016. Subyek penelitian ini adalah seluruh mahasiswa S1 Pendidikan Bidan Universitas Airlangga yang berusia kurang dari atau sama dengan 20 tahun. Penelitian ini menggunakan total sampling. Pengumpulan data dilakukan dengan pengukuran tinggi badan menggunakan microtoice dan memasukkan hasil pengukuran pada grafik pertumbuhan tinggi badan tehadap umur untuk anak perempuan usia 2-20 tahun dalam kurva baku pertumbuhan CDC 2000, serta pengisian lembar pengumpulan data berupa usia pertama kali merasakan penonjolan puting; usia pertama kali menstruasi, durasi tidur malam dihitung $<7$ jam, 7-8 jam, $>8$ jam; ${ }^{6}$ aktivitas olahraga dalam seminggu dengan kategori kurang $(<2$ jam), cukup (2-3 jam), lebih ( $>3 \mathrm{jam}) ;{ }^{7}$ dan pengalaman melihat pornografi. ${ }^{8}$ Analisis data yang dilakukan adalah univariat dan bivariat menggunakan uji Mann Whitney. Penyajian data dalam bentuk tabel dan narasi. Penelitian ini telah dinyatakan layak etik dengan nomor 452/EC/KEKP/FKUA/2016 oleh komite etik Fakultas Kedokteran Universitas Airlangga Surabaya.

\section{HASIL}

Penelitian ini didapatkan 102 mahasiswi yang berusia antara 17-20 tahun dengan sebagian besar memiliki tinggi badan normal $(91,2 \%)$. Secara keseluruhan, usia pubertas dan menarche mahasisiwi dalam rentang usia normal, dengan sebagian besar mengalami pubertas di usia 10 tahun $(60,8 \%)$ dan menarche di usia 12 tahun $(36,3 \%)$. Hampir secara keseluruhan mahasiswi berasal dari Suku Jawa $(91,2 \%)$. Riwayat durasi tidur sebagian besar dalam kategori cukup yaitu antara 7 sampai 8 jam $(78,4 \%)$, tetapi memiliki riwayat aktivitas 
Tabel 1. Distribusi Karakteristik

\begin{tabular}{|c|c|c|}
\hline Karakteristik & n (102) & $\%$ \\
\hline \multicolumn{3}{|l|}{ Tinggi Badan } \\
\hline Pendek & 9 & 8,8 \\
\hline Normal & 93 & 91,2 \\
\hline \multicolumn{3}{|l|}{ Umur } \\
\hline 17 tahun & 1 & 1,0 \\
\hline 18 tahun & 28 & 27,4 \\
\hline 19 tahun & 61 & 59,8 \\
\hline 20 tahun & 12 & 11,8 \\
\hline \multicolumn{3}{|l|}{ Suku Bangsa } \\
\hline Jawa & 93 & 91,2 \\
\hline Madura & 4 & 3,9 \\
\hline Bali & 3 & 2,9 \\
\hline Papua & 1 & 1,0 \\
\hline NTT & 1 & 1,0 \\
\hline \multicolumn{3}{|l|}{ Usia Pubertas } \\
\hline 8 tahun & 5 & 4,9 \\
\hline 9 tahun & 14 & 13,7 \\
\hline 10 tahun & 62 & 60,8 \\
\hline 11 tahun & 0 & 0 \\
\hline 12 tahun & 0 & 0 \\
\hline Lupa & 21 & 20,6 \\
\hline \multicolumn{3}{|l|}{ Usia Menarche } \\
\hline 10 tahun & 4 & 3,9 \\
\hline 11 tahun & 8 & 7,9 \\
\hline 12 tahun & 37 & 36,3 \\
\hline 13 tahun & 29 & 28,4 \\
\hline 14 tahun & 13 & 12,7 \\
\hline 15 tahun & 11 & 10,8 \\
\hline \multicolumn{3}{|l|}{ Durasi tidur } \\
\hline$<7$ jam & 7 & 6,9 \\
\hline $7-8 \mathrm{jam}$ & 80 & 78,4 \\
\hline$>8$ jam & 15 & 14,7 \\
\hline \multicolumn{3}{|l|}{ Aktivitas olahraga } \\
\hline Kurang & 78 & 76,5 \\
\hline Cukup & 13 & 12,7 \\
\hline Lebih & 11 & 10,8 \\
\hline \multicolumn{3}{|l|}{ Melihat Pornografi } \\
\hline Pernah & 62 & 60,8 \\
\hline Tidak Pernah & 40 & 39,2 \\
\hline
\end{tabular}

Sumber : Data primer, 2016

olahraga yang kurang (76,5\%). Sebagian besar mahasiswi mengatakan pernah melihat pornografi $(60,8 \%)$ (Tabel 1).

Hasil uji statistik Mann Whitney antara usia pubertas dengan tinggi badan diperoleh nilai $p=0,643$. Hal ini berarti tidak terdapat perbedaan bermakna antara usia pubertas mahasiswi yang memiliki tinggi badan pendek dengan usia pubertas mahasiswi yang memiliki tinggi badan normal.
Begitu pula hasil uji statistik usia menarche dengan tinggi badan diperoleh nilai $\mathrm{p}=0,198$, yang berarti tidak terdapat perbedaan bermakna antara usia menarche mahasiswi yang memiliki tinggi badan pendek dengan usia menarche mahasiswi yang memiliki tinggi badan normal (Tabel 2).

\section{PEMBAHASAN}

Penelitian ini didapatkan 102 mahasiswi yang berusia 17-20 tahun dengan pertambahan tinggi badan yang pesat pada masa remaja akan mulai melambat dan berhenti pada usia ini. ${ }^{3} \mathrm{Ham}-$ pir keseluruhan mahasiswi memiliki tinggi badan normal. Pertumbuhan tinggi badan dapat dipengaruhi oleh beberapa faktor seperti faktor genetik dan lingkungan biopsikososial yang saling mendukung. ${ }^{4,9}$

Pada penelitian ini, pencapaian tinggi badan yang normal mungkin dapat disebabkan oleh riwayat durasi tidur yang cukup baik (7-8 jam). Durasi tidur di malam hari memiliki peran penting dalam mendukung pertumbuhan tinggi badan. ${ }^{10}$ Hormon pertumbuhan (Growth Hormone/GH) berfungsi sebagai simulator pertumbuhan dan pembelahan sel di setiap bagian tubuh dan tulang rawan, serta meningkatkan pertumbuhan struktur rangka. ${ }^{11}$ Pada periode pubertas, GH dikeluarkan dalam jumlah yang cukup besar dan berhubungan dengan proses pacu tumbuh. Sekresi GH meningkat hingga lima kali lipat saat tidur malam sekitar satu jam setelah tidur lelap dimulai, dibandingkan saat terbangun. ${ }^{12}$

Sekresi hormon pertumbuhan juga dipengaruhi oleh aktivitas fisik atau olahraga. ${ }^{11,12}$ Aktivitas fisik atau olahraga berperan penting dalam kesehatan fisik anak dan remaja seperti meningkatkan lean body mass, kekuatan otot dan tulang. ${ }^{7}$ Pada penelitian ini, aktivitas olahraga pada saat pra-pubertas sebagian besar termasuk kurang $(<2$ jam dalam seminggu).

Pertumbuhan tinggi badan mengalami peningkatan kecepatan saat memasuki usia pubertas. Pada penelitian ini, sebagian besar mahasiswi mengalami pubertas dalam rentang waktu normal pubertas yaitu 8-12 tahun. Usia pubertas sering dikaitkan dengan tinggi badan akhir. Anak perempuan yang mengalami pubertas lebih awal akan memiliki tinggi badan yang lebih pendek. ${ }^{13}$ Pubertas yang terjadi dalam rentang usia pubertas 
Tabel 2. Analisis Hubungan Usia Pubertas, Usia Menarche, dengan Tinggi Badan

\begin{tabular}{|c|c|c|c|c|c|c|c|}
\hline \multirow{3}{*}{ Variabel } & \multicolumn{4}{|c|}{ Tinggi Badan } & \multirow{2}{*}{\multicolumn{2}{|c|}{ Jumlah }} & \multirow{3}{*}{$\mathbf{p}$} \\
\hline & \multicolumn{2}{|c|}{ Pendek } & \multicolumn{2}{|c|}{ Normal } & & & \\
\hline & $\mathbf{n}$ & $\%$ & $\mathbf{n}$ & $\%$ & $\mathbf{n}$ & $\%$ & \\
\hline \multicolumn{8}{|l|}{ Usia Pubertas } \\
\hline 8 tahun & 0 & 0 & 5 & 100 & 5 & 100 & 0,643 \\
\hline 9 tahun & 1 & 7,1 & 13 & 92,9 & 14 & 100 & \\
\hline 10 tahun & 5 & 8,1 & 57 & 91,9 & 62 & 100 & \\
\hline 11 tahun & 0 & 0 & 0 & 0 & 0 & 0 & \\
\hline 12 tahun & 0 & 0 & 0 & 0 & 0 & 0 & \\
\hline Lupa & 3 & 14,3 & 18 & 85,7 & 21 & 100 & \\
\hline \multicolumn{8}{|l|}{ Usia Menarche } \\
\hline 10 tahun & 1 & 25 & 3 & 75 & 4 & 100 & 0,198 \\
\hline 11 tahun & 2 & 25 & 6 & 75 & 8 & 100 & \\
\hline 12 tahun & 2 & 5,4 & 35 & 94,6 & 37 & 100 & \\
\hline 13 tahun & 3 & 10,3 & 26 & 89,7 & 29 & 100 & \\
\hline 14 tahun & 1 & 7,7 & 12 & 92,3 & 13 & 100 & \\
\hline 15 tahun & 0 & 0 & 11 & 100 & 11 & 100 & \\
\hline
\end{tabular}

Sumber : Data primer, 2016

normal, tetapi lebih awal memberikan efek negatif pada tinggi akhir berupa tinggi badan yang lebih pendek. ${ }^{14}$

Hasil analisis menunjukkan tidak ditemukan hubungan yang bermakna antara usia pubertas dengan tinggi badan. Hal ini dapat disebabkan oleh pengaruh faktor endokrin yang cukup tinggi pada masa pra-pubertas, khususnya hormon pertumbuhan (Growth Hormone/GH). Durasi tidur yang cukup baik pada masa pra-pubertas dalam penelitian ini menggambarkan bahwa produksi hormon pertumbuhan berjalan dengan optimal sehingga dapat menunjang pencapaian tinggi badan yang normal. Produksi GH yang tidak maksimal akan memengaruhi pertumbuhan tinggi badan anak menjadi tidak optimal. ${ }^{15}$

Pertumbuhan tinggi badan dipengaruhi pula oleh menarche. Saat menstruasi terjadi secara periodik, maka pertumbuhan fisik pada perempuan mulai berakhir dan tinggi badan tidak akan bertambah banyak lagi. ${ }^{5}$ Menarche terjadi pada fase akhir pubertas yaitu sekitar dua sampai tiga tahun setelah awitan pubertas yang ditandai dengan penurunan kecepatan pertumbuhan tinggi badan hingga terjadi penutupan lempeng epifisis dan pertumbuhan tinggi badan terhenti. ${ }^{4}$

Beberapa studi menganalisis hubungan antara tinggi badan dengan usia menarche dan didapatkan bahwa terdapat hubungan yang positif antara usia menarche dengan tinggi badan akhir saat dewasa, tetapi berhubungan negatif dengan berat badan. ${ }^{16}$ Menarche yang terjadi lebih dini berhubungan dengan perawakan pendek saat dewasa ${ }^{17}$ Perempuan yang mencapai menarche pada usia lebih lanjut akan tumbuh lebih tinggi dibandingkan dengan perempuan yang menarche pada usia lebih dini. ${ }^{18,19}$

Pada penelitian ini didapatkan bahwa seluruh mahasiswi mengalami menstruasi dalam rentang usia normal menarche yaitu 10-15 tahun dengan 36,6\% mengalami menarche di usia 12 tahun. Uji statistik didapatkan bahwa tidak terdapat hubungan bermakna antara usia menarche dengan tinggi badan. Hal ini dapat disebabkan karena sebagian besar mahasiswi berasal dari satu keturunan suku bangsa yaitu Jawa, sehingga rata-rata tinggi badan mahasiswa cenderung sama meskipun mengalami menarche di usia yang berbeda. Perbedaan keturunan secara signifikan memberikan pengaruh terhadap perbedaan tinggi badan akhir saat dewasa. ${ }^{20}$

Ras dan suku bangsa memiliki kaitan erat dengan proporsi tubuh. Perbedaan proporsi tubuh terletak pada perbedaan panjang tungkai bawah yang menyebabkan tinggi badan mengalami perbedaan ukuran. Panjang tungkai di dunia bervariasi. Rata-rata tungkai terpanjang dimiliki oleh ras Australoid, yang tinggal di Indonesia Timur dan 
Australia; sedangkan tungkai dengan proporsi terpendek adalah ras Mongoloid yang merupakan nenek moyang suku Jawa. ${ }^{20}$

Sebagian besar mahasiswi mengatakan pernah melihat pornografi, baik melalui media cetak maupun elektronik. Intensitas melihat pornografi berbeda-beda pada setiap individu. Rangsangan media audio-visual yang diperoleh dengan melihat pornografi dapat mempercepat kematangan seksual yang ditandai dengan peningkatan perilaku seksual pada remaja. Remaja yang terpapar media pornografi mempunyai peluang 3,06 kali berperilaku seksual. ${ }^{21}$

\section{KESIMPULAN DAN SARAN}

Tidak terdapat hubungan antara usia pubertas dan usia menarche dengan tinggi badan mahasiswa bidan Universitas Airlangga. Saran bagi masyarakat khususnya orang tua agar lebih memperhatikan kebutuhan dasar pada anak untuk menunjang tercapainya pubertas dan menarche dalam usia normal sehingga anak akan memiliki peluang tumbuh lebih optimal dan dapat mencapai tinggi badan maksimal.

\section{DAFTAR PUSTAKA}

1. Kementrian Kesehatan RI. Riset Kesehatan Dasar 2013. Jakarta : Badan Penelitian dan Pengembangan Kesehatan Kementrian Kesehatan RI; 2013. pp 209-225.

2. United Nations International Children's Emergency Fund (Unicef) Indonesia. Ringkasan Kajian Kesehatan Ibu dan Anak; 2012. pp 1-6.

3. Soetjiningsih. Tumbuh Kembang Anak. Jakarta : Penerbit Buku Kedokteran EGC; 2015. pp 2-15.

4. Soetjiningsih. Pertumbuhan Somatik pada Remaja. Jakarta : Sagung Seto; 2010. pp 1-16.

5. Pulungan AB. Pubertas dan Gangguannya. In: Batubara JRL, Tridjaja B, Pulungan AB, editors. Buku Ajar Endokrinologi Anak. 1st ed. Jakarta : Badan Penerbit IDAI; 2010. pp 85121.

6. Hense S, Barba G, Pohlabeln H, De Henauw S, Marild S, Molnar D, Moreno LA, Hadjigoergiou C, Veidebaum T, Ahrens W. Factors that Influencs Weekday Sleep Durationin European Children. Sleep. 2011; 34: 9-633.

7. Department of Health and Children, Health
Service Executive. The National Guidelines on Physical Activity for Ireland. Dublin: Department of Health and Children; 2014. pp 1-36.

8. Kementrian Hukum dan Hak Asasi Manusia Republik Indonesia. Undang-Undang Republik Indonesia nomor 44 Tahun 2008 tentang Pornografi. Jakarta: Kementrian Hukum dan Hak Asasi Manusia Republik Indonesia; 2008. pp 1-13.

9. Artaria MD. Peran Faktor Sosial-Ekonomi dan Gizi pada Tumbuh Kembang Anak. Jurnal Masyarakat Kebudayaan dan Politik. 2009; 22(1): 49-58.

10. Batubara, JRL, Susanto R, Cahyono HA. Pertumbuhan dan Gangguan Pertumbuhan. In: Buku Ajar Endokrinologi Anak. 1st ed. Jakarta : Badan Penerbit IDAI; 2010. pp 19-37.

11. Guyton, Arthur C, Hall, John E. Buku Ajar Fisiologi Kedokteran. 11th ed. Jakarta: Penerbit Buku Kedokteran EGC; 2007. pp 968-976.

12. Sherwood L. Fisiologi Manusia dari Sel ke Sistem. 6th. ed. Jakarta: Penerbit Buku Kedokteran EGC; 2011. pp 740-746.

13. Yousefi M, Karmaus W, Zhang H, Roberts G, Matthews S, Clayton B, Arshad SH. Relationships between Age of Puberty Onset and Height at Age 18 Years in Girls and Boys. Journal of Pediatrics. 2013; 1-9.

14. Limony Y, Kozieł S, Friger M. Age of Onset of a Normally Timed Pubertal Growth Spurt Affects the Final Height of Children. Pediatr Res. 2015;78(3): 5-351.

15. Zahara DS. Hubungan antara Gangguan Tidur dengan Pertumbuhan pada Anak Usia 3-6 Tahun di Kota Semarang [Skripsi]. Semarang: Universitas Diponegoro; 2013.

16. Gebregyorgis T, Tadesse T, Atenafu A. Prevalence of Thinness and Stunting and Associated Factors among Adolescent School Girls in Adwa Town, North Ethiopia. International Journal of Food Science. 2016;1-8.

17. Al-Agha AE, Hadadi AA, Tatwany BO. Early Puberty and Its Effect on Height in Young Saudi Females: A Cross-Sectional Study. Journal Pediatrics \& Therapeutics. 2015;5(1):1-4.

18. Gharravi AM, Gharravi S, Marjani A, Moradi A, Golalipour MJ. Correlation of Age at Menarche and Height in Iranian Student 
Girls Living in Gorgan-Northeast of Iran. Journal of the Pakistan Medical Association. 2008;58(8):426-429.

19. Ji-Yeong K, In-Hwan O, Eun-Young L, ChangMo O, Kyung-Sik C, Bong-Keun C,Tai-Young Y, Sung-Hee S, Joong-Myung C. The Relation of Menarcheal Age to Anthropometric Profiles in Korean Girls. Journal of Korean Medical
Science. 2010; 25(10):1405-1410.

20. Artaria MD. Pengaruh Faktor Keturunan terhadap Proporsi Tubuh Anak. Jurnal Masyarakat Kebudayaan dan Politik. 2013;26(1):15-24.

21. Nursal DGA. Faktor-Faktor yang Berhubungan dengan Perilaku Seksual Murid SMU Negeri di Kota Padang Tahun 2007. Jurnal Kesehatan Masyarakat. 2008;2(2):175-180. 